\title{
NUTRITIONAL STATUS IS RELATED TO FAT-FREE MASS, EXERCISE CAPACITY AND INSPIRATORY STRENGTH IN SEVERE CHRONIC OBSTRUCTIVE PULMONARY DISEASE PATIENTS
}

\author{
Pollyane Galinari Sabino, ${ }^{\mathrm{I}}$ Bruno Moreira Silva, ${ }^{\mathrm{I}, \mathrm{II}}$ Antonio Fernando Brunetto ${ }^{\mathrm{I}}$ \\ doi: $10.1590 / \mathrm{S} 1807-59322010000600007$
}

Sabino PG, Silva BM, Brunetto AF. Nutritional status is related to fat-free mass, exercise capacity and inspiratory strength in severe copd chronic obstructive pulmonary disease patients. Clinics. 2010;65(6):599-605.

INTRODUCTION: Being overweight or obese is associated with a higher rate of survival in patients with advanced chronic obstructive pulmonary disease (COPD). This paradoxical relationship indicates that the influence of nutritional status on functional parameters should be further investigated.

OBJECTIVE: To investigate the impact of nutritional status on body composition, exercise capacity and respiratory muscle strength in severe chronic obstructive pulmonary disease patients.

METHODS: Thirty-two patients (nine women) were divided into three groups according to their body mass indices (BMI): overweight/obese $\left(25 \leq \mathrm{BMI} \leq 34.9 \mathrm{~kg} / \mathrm{m}^{2}, \mathrm{n}=8\right)$, normal weight $\left(18.5 \leq \mathrm{BMI} \leq 24.9 \mathrm{~kg} / \mathrm{m}^{2}, \mathrm{n}=17\right)$ and underweight $\left(\mathrm{BMI}<18.5 \mathrm{~kg} / \mathrm{m}^{2}\right.$, $\mathrm{n}=7$ ). Spirometry, bioelectrical impedance, a six-minute walking distance test and maximal inspiratory and expiratory pressures were assessed.

RESULTS: Airway obstruction was similar among the groups ( $\mathrm{p}=0.30)$; however, overweight/obese patients had a higher fat-free mass (FFM) index [FFMI $=F F M /$ body weight ${ }^{2}$ (mean \pm SEM: $17 \pm 0.3$ vs. $15 \pm 0.3$ vs. $\left.\left.14 \pm 0.5 \mathrm{~m} / \mathrm{kg}^{2}, \mathrm{p}<0.01\right)\right]$, exercise capacity $(90 \pm 8$ vs. $79 \pm 6$ vs. $57 \pm 8 \mathrm{~m}, \mathrm{p}=0.02)$ and maximal inspiratory pressure ( $63 \pm 7$ vs. $57 \pm 5$ vs. $35 \pm 8 \%$ predicted, $\mathrm{p}=0.03)$ in comparison to normal weight and underweight patients, respectively. In addition, on backward multiple regression analysis, FFMI was the unique independent predictor of exercise capacity (partial $\mathrm{r}=0.52, \mathrm{p}<0.01$ ).

CONCLUSIONS: Severe chronic obstructive pulmonary disease (COPD) patients who were overweight or obese had a greater FFM, exercise capacity and inspiratory muscle strength than patients with the same degree of airflow obstruction who were of normal weight or underweight, and higher FFM was independently associated with higher exercise capacity. These characteristics of overweight or obese patients might counteract the drawbacks of excess weight and lead to an improved prognosis in COPD.

KEYWORDS: Chronic obstructive pulmonary disease; Body mass index; Body composition; fitness; Respiratory muscle strength.

\section{INTRODUCTION}

There is an association between body mass index (BMI) and increased early mortality in the general population. ${ }^{1,2}$ However, while in some studies, both low and high BMI have been associated with increased mortality (i.e., mortality

\footnotetext{
I Laboratory of Research on Pulmonary Physical Therapy (LFIP), Department of Physical Therapy, Londrina State University (UEL) - Londrina, Paraná, Brazil.

II Laboratory of Exercise Sciences (LACE), Department of Physiology and Pharmacology, Federal Fluminense University (UFF) - Niterói/RJ, Brazil. Email: sabino.pg@gmail.com

Tel: 5521 2629-2403

Received for publication on February 15, 2010

First review completed on March 10, 2010

Accepted for publication on March 18, 2010
}

plotted as a function of BMI has a U-shaped curve), ${ }^{1,2}$ other studies have shown an association between high BMI and increased mortality (i.e., mortality plotted as a function of BMI has a J-shaped curve). ${ }^{1,2}$ In this sense, subjects with low BMI present with a higher risk of death due to cerebrovascular disease, pneumonia, and diseases of the central nervous system. ${ }^{1,2}$ On the other hand, increased fat mass (FM) is associated with the development of several chronic diseases, particularly those of the cardiovascular system. ${ }^{1,2}$

Patients with chronic obstructive pulmonary disease (COPD) generally present with difficulty in breathing, ${ }^{3}$ inadequate dietary intake due to difficulties in ingesting food $^{4}$ and excessive apoptosis of skeletal muscle due to 
increased systemic inflammation. ${ }^{5}$ These and other factors lead to a negative energy balance and decreasing body weight over the course of the disease, with the reduction in body weight occurring mainly as a result of a decrease in skeletal muscle mass. ${ }^{6,7}$ It has been shown that the BMI is an independent predictor of mortality in COPD patients. ${ }^{6,7}$ Nonetheless, the association between BMI and mortality seems to differ according to the severity of COPD. Patients with mild COPD present a bi-modal association between BMI and mortality (i.e., mortality plotted as a function of BMI has a U-shaped curve), with the lowest risk of death occurring in normal weight to overweight patients. Among patients suffering from severe COPD, mortality rate decreases with increasing BMI (i.e., overweight and obese patients have lower mortality rate). ${ }^{8-10}$ The observed lower risk of death in overweight and obese patients with COPD has been called "the obesity paradox"; ${ }^{11}$ although its mechanism is still unknown, the obesity paradox seems to be partly related to the presence of higher fat-free mass (FFM) in these patients. ${ }^{6}$

Exercise intolerance is a major symptom of patients with COPD. ${ }^{12}$ Its cause has been shown to be multifactorial and to depend on impairments in airway flow, pulmonary mechanics, metabolic pathways, gas exchange, cardiac performance, respiratory and peripheral muscles and other factors. ${ }^{13}$ In this context, various studies have investigated the influence of nutritional status on exercise capacity; it is generally agreed that patients with a low BMI, which is most often due to low FFM, show lower exercise capacity on submaximal and maximal exercise tests. ${ }^{8,14-20}$ However, most of these studies investigated severe COPD patients who were underweight or of normal weight. ${ }^{15,16,19}$ Some studies have included overweight or obese patients, but they did not analyze these patients separately. ${ }^{8,14,18,21}$

The few previous studies that present data on the influence of being overweight or obese on the exercise capacity of patients with severe COPD report conflicting results. For example, Esnner et al. ${ }^{20}$ showed that obese men and women presented lower exercise capacity than normal weight counterparts independent of age, height, $\mathrm{FEV}_{1} / \mathrm{FVC}$ ratio, race, education and smoking. However, these authors included patients with mild to severe COPD and did not use the degree of airway obstruction [forced expiratory volume at $\left.1 \mathrm{~s}\left(\mathrm{FEV}_{1}\right)\right]$ in the adjusted models. Ischaki et al. ${ }^{17}$ showed a positive association between BMI and exercise capacity in patients with mild to severe COPD; however, their results show no clear association between nutritional status and exercise capacity in severe COPD patients who are overweight or obese. Thus, the influence of nutritional status on the exercise capacity of overweight or obese COPD patients is still unknown.
Our aim was to investigate the impact of nutritional status on body composition, exercise capacity and respiratory muscle strength in patients with severe COPD. We hypothesized that patients who were overweight or obese would have a greater FFM than patients who were of normal weight or underweight. Considering that the major contributor to FFM is skeletal muscle mass, we hypothesized that a greater FFM would lead to greater exercise capacity, in part due to greater respiratory muscle strength.

\section{METHODS}

\section{Sample}

Thirty-two patients (nine women) with severe COPD participated in this prospective cross-sectional study. The patients were enrolled at the pulmonary outpatient clinic of the University Hospital of the Londrina State University. The diagnosis of COPD was based on past smoking history, clinical evaluation and pulmonary function tests showing irreversible airflow obstruction. ${ }^{12}$ All patients with COPD were in a stable state at study entry (no exacerbations in the last three months that required a change in medication or hospital admission), were not currently smoking and were undergoing standard pharmacological treatment for COPD. ${ }^{12}$ None of the patients were undergoing long-term oxygen therapy. The classification of COPD severity followed the GOLD guidelines, ${ }^{12}$ i.e., severe COPD represented $\mathrm{FEV}_{1}<$ $50 \%$ of predicted value. Patients with orthopedic, neurologic or unstable cardiac diseases that might interfere with the results were excluded. The patients were divided into three groups according to the World Health Organization stratification of BMI: ${ }^{22}$ overweight/obese (BMI between 25 and $29.9 \mathrm{~kg} / \mathrm{m}^{2}, \mathrm{n}=6$; BMI between 30 and $34.9 \mathrm{~kg} /$ $\mathrm{m}^{2}, \mathrm{n}=2$ ), normal weight (BMI between 18.5 and $24.9 \mathrm{~kg} /$ $\left.\mathrm{m}^{2}, \mathrm{n}=17\right)$ and underweight $\left(\mathrm{BMI}<18.5 \mathrm{~kg} / \mathrm{m}^{2}, \mathrm{n}=7\right)$. Overweight and obese patients were analyzed together due to the small number of obese patients in our sample. The ethics committee of the North Paraná University Hospital approved the research protocol and a written consent form was obtained for each patient.

\section{Spirometry}

Spirometry was performed using a turbine portable spirometer (Pony, Cosmed, Rome, Italy) according to American Thoracic Society guidelines. ${ }^{23}$ The $\mathrm{FEV}_{1}$, forced vital capacity (FVC) and maximal voluntary ventilation (MVV) were obtained and expressed as percentage of predicted according to Knudson et al. ${ }^{24}$ 


\section{Anthropometry}

Body weight was measured on a calibrated balance to the nearest $0.1 \mathrm{~kg}$ while patients were barefoot and wearing light clothing (Filizola model 31, Filizola, São Paulo, SP, Brazil). Body height was measured to the nearest $0.5 \mathrm{~cm}$ while patients were barefoot and standing with their backs and heels touching a vertical bar (Filizola model 31, Filizola, São Paulo, SP, Brazil). BMI was calculated as weight divided by height squared $\left(\mathrm{kg} / \mathrm{m}^{2}\right)$.

\section{Body Composition}

Body composition was assessed by single-frequency bioelectrical impedance analysis (Biodynamics 310, Biodynamics Corporation, Seattle, WA, USA). All body composition measurements were performed between noon and 2 p.m. The patients fasted on the day that the measurement was performed and did not ingest coffee, tea, chocolate or alcoholic beverages for $48 \mathrm{~h}$ prior to the measurement. During the measurement, patients lay in a supine position with their limbs slightly apart from their bodies. Two electrodes were positioned on the dorsal surface of the right hand, and two additional electrodes were positioned on the dorsal surface of the right foot. The FFM was calculated using an equation that has been specifically validated for patients with respiratory diseases. ${ }^{25} \mathrm{FM}$ was calculated as total body weight minus FFM. FFM index (FFMI) and FM index (FMI) were calculated by dividing the body weight (in $\mathrm{kg}$ ) of FFM and FM, respectively, by height (in $\mathrm{m}$ ) squared in order to adjust for body surface area. ${ }^{26}$ It is important to note that the known prerequisites for the use of bioelectrical impedance analysis, which include patient preparation prior to the measurement, adaptation of equations used to transform the measured resistance into FFM or total body volume and testing of the validity of the use of these equations in the populations for which they are intended, were followed in the present study. Under these conditions, bioeletrical impedance analysis measurements are considered accurate and comparable to other techniques used to assess body composition..$^{25}$

\section{Exercise Capacity}

The exercise capacity was assessed by the six-minute walking distance test (6MWD), which is validate ${ }^{27}$ and reliable ${ }^{28}$ for evaluation of the exercise capacity of patients with COPD. The test was performed in a 15-m long and 4-m wide hospital corridor. All of the patients were familiarized with the test procedure prior to testing. Patients were instructed to walk as fast as possible, aiming to complete the longest possible distance in the allotted time. At each full minute during the test, the patients were verbally encouraged with a standardized incentive phrase. Each patient's result was expressed as an absolute value (meters) and as a percentage of the normal values. ${ }^{29}$

\section{Respiratory Muscle Strength}

The strength of the respiratory muscles was evaluated by measuring the maximal inspiratory pressure $\left(\mathrm{PI}_{\max }\right)$ and maximal expiratory pressure $\left(\mathrm{PE}_{\max }\right)$ using an analog manovacuometer built by Record ${ }^{\circledR}$ (São Paulo, SP, Brazil). The range of measurement was $\pm 150 \mathrm{~cm} \mathrm{H}_{2} \mathrm{O}$. The manovacuometer was connected to an inextensible rubber hose of $38 \mathrm{~cm}$ in length and $0.5 \mathrm{~cm}$ in diameter; the hose was connected to a mouthpiece with a $2-\mathrm{mm}$ hole to avoid any influence of intra-oral pressure on the measurements. Patients were evaluated in the seated position. A nose clip was used to avoid air leakage through the nostrils. For the $\mathrm{PI}_{\max }$ measurement, the patients began at the residual volume level and performed a maximal inspiration until total lung capacity was reached. For the $\mathrm{PE}_{\max }$ measurement, the patients began at total lung capacity and performed a maximal expiration until only residual volume remained. Maximal pressures were expected to be sustained for at least one second. For each measurement, three attempts were made and the highest value was used. Expected values for $\mathrm{PI}_{\text {max }}$ and $\mathrm{PE}_{\max }$ were calculated according to Black and Hyatt. ${ }^{30}$

\section{Statistical Analysis}

Data distribution was verified by the Shapiro-Wilk test. Only $\mathrm{FEV}_{1} / \mathrm{FVC}(\%)$ and FMI presented nonparametric distributions. The groups were compared by one-way ANOVA followed by the Sheffé post hoc, or, when necessary, by the Kruskal-Wallis test followed by multiple comparisons ( $\mathrm{z}$ - values). In addition, a backward stepwise multiple regression analysis was performed. The intercept was included in the regression model. The tolerance was set at 0.1 , the ' $F$ to enter' at 4 and the ' $F$ to remove' at 3.9. These ' $F$ to enter and remove' values were chosen in order to detect variables that were significant at $p<0.05$. The walking distance, expressed as a percentage value, was considered as the dependent variable, and only the variables that were significantly associated with the walking distance in Pearson's correlations were used in the multiple regression analyses. The results are presented as mean \pm standard error of the mean (SEM). A p-value lower than 0.05 was considered significant in two-tailed analyses. All analyses were performed using STATISTICA version 7 software (StatSoft, Tulsa, OK, USA). 
Table 1 - Characteristics of the patients according to their nutritional status.

\begin{tabular}{|c|c|c|c|c|}
\hline Characteristics & Overweight/Obese & Normal weight & Underweight & ANOVA (p) \\
\hline $\operatorname{Sex}(M / F)$ & $6 / 2$ & $11 / 6$ & $6 / 1$ & - \\
\hline Age (years) & $63 \pm 4$ & $63 \pm 2$ & $68 \pm 4$ & 0.60 \\
\hline $\mathrm{FEV}_{1}(\%)$ & $34 \pm 4$ & $34 \pm 2$ & $27 \pm 4$ & 0.30 \\
\hline $\mathrm{FEV}_{1} / \mathrm{FVC}(\%)$ & $64 \pm 6$ & $59 \pm 4$ & $49 \pm 4$ & 0.19 \\
\hline MVV (\%) & $36 \pm 4$ & $31 \pm 3$ & $27 \pm 4$ & 0.31 \\
\hline Weight (kg) & $80 \pm 4 * \dagger$ & $59 \pm 2 \ddagger$ & $44 \pm 3$ & $<0.01$ \\
\hline Height (m) & $1.68 \pm 0.03$ & $1.61 \pm 0.03$ & $1.61 \pm 0.04$ & 0.23 \\
\hline BMI $\left(\mathrm{kg} / \mathrm{m}^{2}\right)$ & $28.4 \pm 0.8 * \dagger$ & $22.0 \pm 0.5 \ddagger$ & $17.1 \pm 0.4$ & $<0.01$ \\
\hline FFMI $\left(\mathrm{kg} / \mathrm{m}^{2}\right)$ & $17.3 \pm 0.3 * \dagger$ & $15.3 \pm 0.3 \ddagger$ & $13.7 \pm 0.5$ & $<0.01$ \\
\hline FMI $\left(\mathrm{kg} / \mathrm{m}^{2}\right)$ & $11.1 \pm 0.9 * \dagger$ & $7.6 \pm 0.9$ & $3.4 \pm 0.5$ & $<0.01$ \\
\hline Walking distance (\%) & $90 \pm 8 * \dagger$ & $79 \pm 6$ & $57 \pm 8$ & 0.03 \\
\hline $\mathrm{PI}_{\max }(\%)$ & $63 \pm 7 * \dagger$ & $57 \pm 5$ & $35 \pm 8$ & 0.03 \\
\hline $\mathrm{PE}_{\max }(\%)$ & $62 \pm 8$ & $50 \pm 5$ & $50 \pm 8$ & 0.43 \\
\hline
\end{tabular}

Results presented as mean \pm SEM. *, $p<0.05$ overweight/obese vs. normal weight; $\dagger, \mathrm{p}<0.05$ overweight/obese vs. underweight; $\neq, \mathrm{p}<0.05$ normal weight vs. underweight. $\mathrm{FEV}_{1}$, forced expiratory volume at $1 \mathrm{~s} ; \mathrm{FEV}_{1} / \mathrm{FVC}$, ratio between forced expiratory volume in $1 \mathrm{~s}$ and forced vital capacity; MVV, maximal voluntary ventilation; BMI, body mass index; FFMI, fat- free mass index; FMI, fat mass index; $\mathrm{PI}_{\max }$, maximal inspiratory pressure; $\mathrm{PE}_{\max }$, maximal expiratory pressure.

\section{RESULTS}

The spirometry, anthropometry, body composition, exercise capacity and respiratory muscle strength results are presented in Table 1, which is organized by the patients' nutritional status. There were no statistically significant differences among the groups in age, height, $\mathrm{FEV}_{1}, \mathrm{FEV}_{1} /$ FVC or MVV. However, the overweight/obese group had significantly higher body weight, BMI, FFMI, FMI, walking distance $(449 \pm 36 \mathrm{~m}$ vs. $410 \pm 32 \mathrm{~m}$ vs. $280 \pm 37 \mathrm{~m}$, $\mathrm{p}=0.02$; overweight vs. normal weight vs. underweight, respectively) and $\mathrm{PI}_{\max }$ compared to the normal weight and underweight groups. Moreover, the normal weight group had higher weight, BMI and FFMI in comparison to the underweight group. It is worth noting that the power for the ANOVA comparisons presented in Table 1 was as follows: age $=0.19, \mathrm{FEV}_{1}=0.42, \mathrm{FEV}_{1} / \mathrm{FVC}=0.64, \mathrm{MVV}=0.42$, weight $=1.00$, height $=0.42, \mathrm{BMI}=1.00, \mathrm{FFMI}=1.00$, walking distance $=0.87, \mathrm{PI}_{\max }=0.91, \mathrm{PE}_{\max }=0.26$.

The correlations between walking distance and age, spirometry, body composition and respiratory muscle strength are presented in Table 2. There were significant correlations between walking distance and $\mathrm{FEV}_{1} / \mathrm{FVC}$, weight, BMI, FFMI and PI ${ }_{\max }$. Therefore, these variables were used in a backward stepwise multiple linear regression analysis, which showed that FFMI was the unique significant independent predictor of walking distance (partial $r=0.52, p$ $<0.001$ ) (Table 3). The correlation between walking distance and FFMI is presented in detail in Figure 1.
Table 2 - Pearson correlation between walking distance (\%) and age, spirometry, body composition and respiratory muscle strength.

\begin{tabular}{|c|c|c|}
\hline & \multicolumn{2}{|c|}{ Walking Distance (\%) } \\
\hline & $\mathbf{r}$ & $\mathbf{p}$ \\
\hline Age (years) & -0.02 & 0.90 \\
\hline $\operatorname{FEV}_{1}(\%)$ & 0.32 & 0.08 \\
\hline $\mathrm{FEV}_{1} / \mathrm{FVC}(\%)$ & 0.38 & 0.03 \\
\hline $\operatorname{MVV}(\%)$ & 0.23 & 0.21 \\
\hline Weight (kg) & 0.38 & 0.03 \\
\hline Height (m) & 0.06 & 0.74 \\
\hline $\operatorname{BMI}\left(\mathrm{kg} / \mathrm{m}^{2}\right)$ & 0.38 & 0.03 \\
\hline FFMI $\left(\mathrm{kg} / \mathrm{m}^{2}\right)$ & 0.52 & $<0.01$ \\
\hline FMI $\left(\mathrm{kg} / \mathrm{m}^{2}\right)$ & 0.29 & 0.10 \\
\hline $\mathrm{PI}_{\max }(\%)$ & 0.47 & $<0.01$ \\
\hline $\mathrm{PE}_{\max }(\%)$ & -0.04 & 0.84 \\
\hline
\end{tabular}

$\mathrm{FEV}_{1}$, forced expiratory volume at $1 \mathrm{~s} ; \mathrm{FEV}_{1} / \mathrm{FVC}$, ratio between forced expiratory volume in $1 \mathrm{~s}$ and forced vital capacity; MVV, maximal voluntary ventilation; BMI, body mass index; FFMI, fat- free mass index; FMI, fat mass index; $\mathrm{PI}_{\max }$, maximal inspiratory pressure; $\mathrm{PE}_{\max }$, maximal expiratory pressure.

\section{DISCUSSION}

The few previous studies that present data on the influence of being overweight or obese on the exercise capacity of patients with severe COPD report conflicting results. ${ }^{17,20}$ Therefore, the present study aimed to investigate the impact of 
Table 3 - Partial correlations obtained with backward multiple regression analysis.

\begin{tabular}{lcc}
\hline & \multicolumn{2}{c}{ Walking Distance $(\%)$} \\
\cline { 2 - 3 } & $\mathbf{r}$ & $\mathbf{r}$ \\
\hline $\begin{array}{l}\text { Variables not in the } \\
\text { equation }\end{array}$ & \\
$\mathrm{FEV}_{1} / \mathrm{FVC}(\%)$ & 0.23 & 0.20 \\
Weight $(\mathrm{kg})$ & -0.03 & 0.89 \\
$\mathrm{BMI}\left(\mathrm{kg} / \mathrm{m}^{2}\right)$ & -0.03 & 0.90 \\
$\mathrm{PI}_{\text {max }}(\%)$ & 0.29 & 0.16 \\
Variable in the equation & & \\
FFMI $\left(\mathrm{kg} / \mathrm{m}^{2}\right)$ & 0.52 & $<0.01$ \\
\hline
\end{tabular}

$\mathrm{FEV}_{1}$, forced expiratory volume at $1 \mathrm{~s} ; \mathrm{FEV}_{1} / \mathrm{FVC}$, ratio between forced expiratory volume in $1 \mathrm{~s}$ and forced vital capacity; MVV, maximal voluntary ventilation; BMI, body mass index; FFMI, fat- free mass index; FMI, fat mass index; $\mathrm{PI}_{\max }$, maximal inspiratory pressure; $\mathrm{PE}_{\max }$, maximal expiratory pressure. FFMI was the unique significant independent predictor of walking distance.

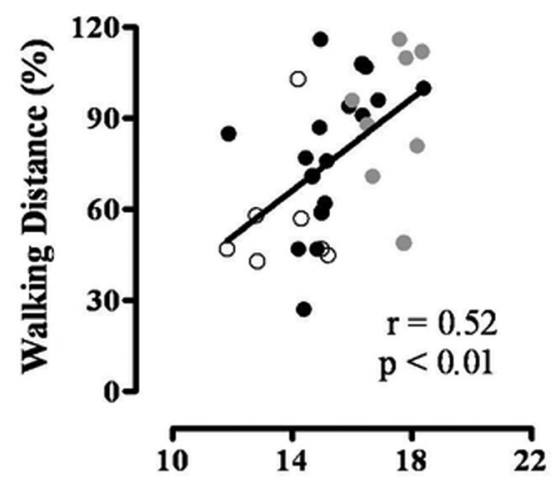

Fat Free Mass Index $\left(\mathrm{kg} / \mathrm{m}^{2}\right)$

Figure 1 - Association between fat-free mass index (FFMI) and exercise capacity. Gray circles represent patients who are overweight/obese; black circles represent patients who are of normal weight; white circles represent patients who are underweight.

nutritional status on the body composition, exercise capacity and respiratory muscle strength of patients with severe COPD. We found that the overweight/obese patients had greater FFM, exercise capacity and respiratory muscle strength and that FFM was the main predictor of exercise capacity.

The higher exercise capacity found in this study in patients with severe COPD who were overweight/obese is supported by the results of Ischaki el al. ${ }^{17}$ Celli et al. ${ }^{8}$ and Cote et al., ${ }^{21}$ who included overweight and obese patients in their samples but did not analyze overweight and obese subjects separately from normal weight subjects. These studies show a positive association between BMI and exercise capacity. Nonetheless, it is worth noting that FFM and FM contribute to the BMI. Therefore, it is important to analyze the association between nutritional status and exercise capacity taking into account the contributions of
FFM and FM separately. In this context, VanItallie et al. ${ }^{26}$ proposed expression of FFM and FM normalized to the square of the height; these parameters have been designated FFMI and FMI, respectively. The FFMI has been shown to be more useful than the BMI in identifying subjects with protein-energy malnutrition, and it has been shown to be more accurate for classifying disease severity ${ }^{17}$ and predicting mortality in patients with COPD. ${ }^{6}$

In this context, the data obtained by our bioimpedance measurements demonstrated that overweight/obese patients presented higher FFMI and FMI in comparison to normal weight and underweight patients. This result is similar to that of Poulain et al., ${ }^{31}$ who showed that COPD patients who are overweight/obese tend to present with higher FFM. In our study, the FFMI was the main significant predictor of exercise capacity in a backward multiple linear regression analysis. Indeed, it has previously been shown that patients with normal weight and depleted FFM have lower exercise capacity in comparison to underweight patients with relative preservation of FFM..$^{32}$ Our results suggest that the overweight/obese patients in our study had higher exercise capacity due to their higher FFM.

The role of FFM as a determinant of higher exercise capacity might result from its influence on several important factors. Because skeletal muscle mass is the major contributor to FFM and because respiratory muscle strength has been shown to affect the exercise capacities of normal and underweight patients with COPD, ${ }^{33}$ we attempted to determine whether differences in respiratory muscle function could explain the observed differences in exercise capacity between the various groups. While we found that obese/overweight patients had higher respiratory muscle strength than patients who were underweight, no variable representative of respiratory muscle function was a significant predictor of exercise capacity. These results suggest that peripheral skeletal muscles may make a more important contribution to exercise capacity than respiratory muscles. However, because peripheral muscle function was not measured in the present study, we can only speculate about this contribution.

It is important to note that, for the general population, mechanistic studies, studies regarding metabolic risk factors and studies regarding cardiovascular disease and premature mortality have shown that a high amount of body fat is associated with an increased risk of cardiovascular disease and early mortality. ${ }^{34}$ Despite this evidence, recent studies indicate that exercise capacity can modulate the harm caused by excessive body fat. For example, McAuley et al. evaluated 12,417 veterans aged 40 to 70 years and showed that overweight and obese men had increased longevity only if they registered high fitness. ${ }^{2}$ Considering that exercise 
capacity is strongly related to prognosis for several diseases including $\mathrm{COPD}^{8,21}$ and that the present study and others ${ }^{8,17,21}$ have shown that overweight/obese patients present higher exercise capacity than normal weight or underweight patients, the relationship between overweight/obesity and exercise capacity may represent a plausible mechanism to explain why severe COPD patients who are overweight or obese have a better prognosis. We found that the overweight/ obese patients had a greater FFM and higher respiratory muscle strength. Because it has been shown that FFM is an independent predictor of death ${ }^{6}$ and that respiratory muscle strength is associated with better functional status, both of these factors could also explain why severe COPD patients with overweight/obesity have better prognoses.

The results of the present study should be interpreted in view of some limitations. Based on high-resolution computed tomographic scanning, loss of FFM appears to be more frequent in patients with emphysema-type COPD than in patients with chronic bronchitis. ${ }^{35}$ We were unable to differentiate COPD subtypes in our sample. In addition, because there were few obese patients in our sample, we analyzed them together with overweight patients. It is worth noting that, for the most important comparisons between groups, the statistical analysis of the study data possessed more than $80 \%$ power to detect significant differences at a p-value lower than 0.05 . Because patients with more severe obesity might present with lower exercise capacity, lower respiratory muscle strength and other dysfunctions associated with metabolic syndrome that could lead to a worse prognosis, other studies should attempt to determine the degree of obesity that reflects a better functional status for COPD patients. Other cohort studies using mortality as an endpoint are necessary to confirm that FFM, exercise capacity and respiratory muscle strength promote longer life in overweight/obese severe COPD patients.

\section{CONCLUSIONS}

Severe COPD patients who were overweight/obese had greater FFM, exercise capacity and inspiratory muscle strength than patients with the same degree of airflow obstruction who were of normal weight or underweight. Higher FFM was independently associated with higher exercise capacity. Considering that FFM and exercise capacity are independent predictors of death and that respiratory muscle strength is associated with functional capacity, our results might explain, at least in part, why being overweight or obese is often associated with better survival in patients with severe COPD.

\section{ACKNOWLEDGEMENTS}

The authors are grateful to Mari M. Lee for revising the language used in the manuscript. Pollyane Galinari Sabino and Bruno Moreira Silva received scholarships from the National Council of Technological and Scientific Development (CNPq). LFIP was supported by the Araucaria Foundation.

\section{REFERENCES}

1. Calle EE, Thun MJ, Petrelli JM, Rodriguez C, Heath CW Jr. Body-mass index and mortality in a prospective cohort of U.S. adults. N Engl J Med. 1999;341:1097-105.

2. McAuley PA, Kokkinos PF, Oliveira RB, Emerson BT, Myers JN Obesity paradox and cardiorespiratory fitness in 12,417 male veterans aged 40 to 70 years. Mayo Clin Proc. 2010;85:115-21.

3. Evison H, Cherniack RM. Ventilatory cost of exercise in chronic obstructive pulmonary disease. J Appl Physiol. 1968;25:21-7.

4. Ferreira IM, Brooks D, Lacasse Y, Goldstein RS. Nutritional support for individuals with COPD: a meta-analysis. Chest. 2000;117:672-8.

5. Agusti AG, Sauleda J, Miralles C, Gomez C, Togores B, Sala E, et al. Skeletal muscle apoptosis and weight loss in chronic obstructive pulmonary disease. Am J Respir Crit Care Med. 2002;166:485-9.

6. Schols AM, Broekhuizen R, Weling-Scheepers CA, Wouters EF. Body composition and mortality in chronic obstructive pulmonary disease. Am J Clin Nutr. 2005;82:53-9.
7. Vestbo J, Prescott E, Almdal T, Dahl M, Nordestgaard BG, Andersen $\mathrm{T}$, et al. Body mass, fat-free body mass, and prognosis in patients with chronic obstructive pulmonary disease from a random population sample: findings from the Copenhagen City Heart Study. Am J Respir Crit Care Med. 2006;173:79-83.

8. Celli BR, Cote CG, Marin JM, Casanova C, Montes de Oca M, Mendez RA, et al. The body-mass index, airflow obstruction, dyspnea, and exercise capacity index in chronic obstructive pulmonary disease. $\mathrm{N}$ Engl J Med. 2004;350:1005-12.

9. Landbo C, Prescott E, Lange P, Vestbo J, Almdal TP. Prognostic value of nutritional status in chronic obstructive pulmonary disease. Am J Respir Crit Care Med. 1999;160:1856-61.

10. Schols AM, Slangen J, Volovics L, Wouters EF. Weight loss is a reversible factor in the prognosis of chronic obstructive pulmonary disease. Am J Respir Crit Care Med. 1998;157:1791-7.

11. Poulain M, Doucet M, Major GC, Drapeau V, Series F, Boulet LP, et al. The effect of obesity on chronic respiratory diseases: pathophysiology and therapeutic strategies. CMAJ. 2006;174:1293-9. 
12. Rabe KF, Hurd S, Anzueto A, Barnes PJ, Buist SA, Calverley P, et al. Global strategy for the diagnosis, management, and prevention of chronic obstructive pulmonary disease: GOLD executive summary. Am J Respir Crit Care Med. 2007;176:532-55.

13. Pepin V, Saey D, Laviolette L, Maltais F. Exercise capacity in chronic obstructive pulmonary disease: mechanisms of limitation. COPD. 2007;4:195-204.

14. Palange P, Forte S, Onorati P, Paravati V, Manfredi F, Serra P, et al. Effect of reduced body weight on muscle aerobic capacity in patients with COPD. Chest. 1998;114:12-8.

15. Yoshikawa M, Yoneda T, Takenaka H, Fukuoka A, Okamoto Y, Narita $\mathrm{N}$, et al. Distribution of muscle mass and maximal exercise performance in patients with COPD. Chest. 2001;119:93-8.

16. Schols AM, Mostert R, Soeters PB, Wouters EF. Body composition and exercise performance in patients with chronic obstructive pulmonary disease. Thorax. 1991;46:695-9.

17. Ischaki E, Papatheodorou G, Gaki E, Papa I, Koulouris N, Loukides S. Body mass and fat-free mass indices in COPD: relation with variables expressing disease severity. Chest. 2007;132:164-9.

18. Baarends EM, Schols AM, Mostert R, Wouters EF. Peak exercise response in relation to tissue depletion in patients with chronic obstructive pulmonary disease. Eur Respir J. 1997;10:2807-13.

19. Kobayashi A, Yoneda T, Yoshikawa M, Ikuno M, Takenaka H, Fukuoka A, et al. The relation of fat-free mass to maximum exercise performance in patients with chronic obstructive pulmonary disease. Lung. 2000;178:119-27.

20. Eisner MD, Blanc PD, Sidney S, Yelin EH, Lathon PV, Katz PP, et al. Body composition and functional limitation in COPD. Respir Res. 2007;8:7.

21. Cote CG, Pinto-Plata V, Kasprzyk K, Dordelly LJ, Celli BR. The 6-min walk distance, peak oxygen uptake, and mortality in COPD. Chest. 2007;132:1778-85

22. World Health Organization. Obesity: preventing and managing the global epidemic. Report of a WHO consultation. World Health Organ Tech Rep Ser. 2000;894:5-15.

23. Nici L, Donner C, Wouters E, Zuwallack R, Ambrosino N, Bourbeau $\mathrm{J}$, et al. American Thoracic Society/European Respiratory Society statement on pulmonary rehabilitation. Am J Respir Crit Care Med. 2006;173:1390-413.
24. Knudson RJ, Slatin RC, Lebowitz MD, Burrows B. The maximal expiratory flow-volume curve. Normal standards, variability, and effects of age. Am Rev Respir Dis. 1976;113:587-600.

25. Kyle UG, Pichard C, Rochat T, Slosman DO, Fitting JW, Thiebaud D. New bioelectrical impedance formula for patients with respiratory insufficiency: comparison to dual-energy X-ray absorptiometry. Eur Respir J. 1998;12:960-6.

26. VanItallie TB, Yang MU, Heymsfield SB, Funk RC, Boileau RA. Heightnormalized indices of the body's fat-free mass and fat mass: potentially useful indicators of nutritional status. Am J Clin Nutr. 1990;52:953-9.

27. Butland RJ, Pang J, Gross ER, Woodcock AA, Geddes DM. Two-, six-, and 12-minute walking tests in respiratory disease. Br Med J (Clin Res Ed). 1982;284:1607-8.

28. Kervio G, Carre F, Ville NS. Reliability and intensity of the six-minute walk test in healthy elderly subjects. Med Sci Sports Exerc. 2003;35:16974.

29. Enright PL, Sherrill DL. Reference equations for the six-minute walk in healthy adults. Am J Respir Crit Care Med. 1998;158:1384-7.

30. Black LF, Hyatt RE. Maximal respiratory pressures: normal values and relationship to age and sex. Am Rev Respir Dis. 1969;99:696-702.

31. Poulain M, Doucet M, Drapeau V, Fournier G, Tremblay A, Poirier P, et al. Metabolic and inflammatory profile in obese patients with chronic obstructive pulmonary disease. Chron Respir Dis. 2008;5:35-41.

32. Schols AM, Soeters PB, Dingemans AM, Mostert R, Frantzen PJ, Wouters EF. Prevalence and characteristics of nutritional depletion in patients with stable COPD eligible for pulmonary rehabilitation. Am Rev Respir Dis. 1993;147:1151-6.

33. Belman MJ, Mittman C. Ventilatory muscle training improves exercise capacity in chronic obstructive pulmonary disease patients. Am Rev Respir Dis. 1980;121:273-80.

34. Snijder MB, van Dam RM, Visser M, Seidell JC. What aspects of body fat are particularly hazardous and how do we measure them? Int J Epidemiol. 2006;35:83-92.

35. Engelen MP, Schols AM, Lamers RJ, Wouters EF. Different patterns of chronic tissue wasting among patients with chronic obstructive pulmonary disease. Clin Nutr. 1999;18:275-80. 